\title{
SỬ DỤNG PHƯƠNG PHÁP VẤN ĐÁP TRONG DẠY HỌC HỌC PHẦ \\ "PHƯƠNG PHÁP CHO TRẺ KHÁM PHÁ KHOA HỌC \\ VỀ MÔI TRƯỜnG XUNG QUANH"
}

\section{Using oral method in teaching module \\ "Method for children to discover environmental science around"}

Ngày nhận bài: 20/5/2016; ngày phản biện: 27/5/2016; ngày duyệt đăng: 22/3/2017

Phạm Thị Thu Thủy*

\section{TÓM TÁT}

Vận dụng các phương pháp vào dạy học, trong đó có phương pháp dạy học vấn đáp đang được rất nhiều giáo viên áp dụng. Đối với học phần Phương pháp cho trẻ khám phá khoa học về môi trường xung quanh, việc vận dụng phương pháp này càng được các giáo viên quan tâm. Trong đó, việc sử dụng các dạng câu hỏi, thang bậc nhận thức của B.S.Blom giúp việc sắp xếp các câu hỏi theo trình tự, cũng như phù hợp với mức độ nhận thức của người học, nhằm mang lại kết quả cho cả người dạy và người học.

Từ khóa: Phuoong pháp khám phá khoa học về môi truờng xung quanh; môi trương xung quanh; phwơng pháp vấn đáp.

\begin{abstract}
Applying these methods in teaching, including oral teaching method is being applied by more teachers. For module method for children to discover environmental science around, applying this approach has been the teachers concerned. In particular, the use of these types of questions, as well as awareness of BSBlom helps arrange the questions in the order, as well as consistent with the level of awareness of learners, in order to bring results both teachers and learners. .
\end{abstract}

Key words: environmental around; oral method.

\section{1. Đặt vấn đề}

Đổi mới phương pháp dạy học đang được mọi người quan tâm theo phương châm: "Lấy học sinh làm trung tâm”. Để thực hiện được điều đó, trong quá trình dạy học đòi hỏi người giáo viên phải biết phối hợp các phương pháp dạy học một cách linh hoạt, trong đó phương pháp vấn đáp là hoạt động không thể thiếu. Phương pháp này nhằm phát huy tính tích cực, chủ động, sáng tạo của người học trong quá trình học tập.

Với tổng số 60 tiết (41 tiết lí thuyết, 17 tiết thực hành), học phần Phương pháp cho trẻ khám phá khoa học về môi trường xung quanh (MTXQ) dành cho hệ cao đẳng sư phạm mầm non sẽ trang bị cho người học hệ thống những tri thức khoa học cơ bản về phương pháp, hình thức cho trẻ khám phá khoa học về MTXQ. Trên cơ sở đó, người học được thực hành và rèn luyện năng lực nghiệp vụ. Để đạt mục tiêu của học phần, giáo viên cần sử dụng nhiều phương pháp trong đó có phương pháp vấn đáp. Sau đây, tôi xin trao đổi về việc sử dụng phương pháp vấn đáp vào giảng dạy phần " $C a ́ c$ hình thức tổ chức hướng dẫn trẻ khám phá khoa hoc 
về MTXQ".

\section{Khái quát về phương pháp vấn đáp}

\subsection{Khái niệm}

Phương pháp vấn đáp là: "Phương pháp giáo viên khéo léo đặt ra hệ thống câu hỏi để học sinh trả lời nhằm gợi mở cho học sinh sáng tỏ những vấn đề mới, tự khai phá những tri thức mới bằng cách tái hiện những tài liệu đã học hoặc từ những kinh nghiệm đã tích luỹ được trong cuộc sống, nhằm giúp học sinh củng cố, mở rộng, đào sâu, tổng kết, hệ thống hoá tri thức đã tiếp thu được nhằm mục đích kiểm tra, đánh giá, và giúp học sinh tự kiểm tra, tự đánh giá việc lĩnh hội tri thức, kĩ năng kĩ xảo trong quá trình dạy học". [trang 2, Phuoong pháp dạy học theo huớng tích cục - Đặng Văn Đức - Nguyễn Thu Hằng, NXB Giáo dục 1998].

\subsection{Phân loại}

Có nhiều cách phân loại phương pháp vấn đáp khác nhau

- Dựa vào mục đích dạy học, có thể phân ra các loại vấn đáp như sau:

+ Vấn đáp gợi mở: là phương pháp giáo viên khéo léo đặt câu hỏi hoặc một chuỗi câu hỏi, nhằm dẫn dắt người học giải quyết một vấn đề cơ bản, từ đó rút ra kết luận, nhờ vậy mà họ lĩnh hội được tri thức mới.

+ Vấn đáp củng cố: là phương pháp giáo viên khéo léo đặt ra một câu hỏi hoặc hệ thống câu hỏi nhằm giúp người học củng cố, hoặc giúp họ mở rộng, đào sâu những tri thức đã thu lượm được.

+ Vấn đáp tổng kết: là phương pháp vấn đáp nhằm giúp người học khái quát, hệ thống hóa những tri thức sau khi đã học một phần, một bài, một chương, một bộ môn nhất định.

+ Vấn đáp kiểm tra: là phương pháp vấn đáp nhằm kiểm tra những tri thức đã học, đã được củng cố, khái quát, hệ thống hoá. Qua câu trả lời của người học mà giáo viên có thể đánh giá và họ cũng tự kiểm tra, tự đánh giá những tri thức đã được lĩnh hội kịp thời, nhanh gọn.

- Dựa vào tính chất nhận thức của học sinh, có thể phân các loại vấn đáp sau:

+ Vấn đáp giải thích - minh họa: là phương pháp mà giáo viên đặt ra những câu hỏi đòi hỏi người học giải thích, nêu lên dẫn chứng để minh hoạ, làm sáng tỏ sự giải thích của mình. Trong câu trả lời của học sinh, không chỉ đòi hỏi nhớ lại tri thức mà phải có sự cấu trúc lại tri thức để có sự suy luận cần thiết.

+ Vấn đáp tái hiện: là phương pháp giáo viên đặt ra những câu hỏi có tính chất vấn đề, gây cho người học gặp phải tình huống vấn đề, qua đó họ có nhu cầu phải lĩnh hội tri thức mới để giải quyết vấn đề.

\subsection{Xét chất lựng câu hỏi, người ta}

\section{phân chia ra thành hai dạng chính}

- Dạng 1: Những câu hỏi có yêu cầu thấp: đòi hỏi tái hiện các kiến thức, sự kiện, nhớ và trình bày một cách có hệ thống, có chọn lọc.

- Dạng 2: Những câu hỏi có yêu cầu cao: đòi hỏi sự thông hiểu, phân tích, tổng hợp, khái quát hóa, hệ thống hóa, vận dụng kiến thức.

Đi sâu vào trình độ trí tuệ của câu hỏi, nhà bác học người Mỹ Benjamin S.Blom (1956) đề xuất một thang 6 mức, tương ứng với 6 mức chất lượng lĩnh hội kiến thức được thừa nhận khá rộng rãi:

- Mức 1- Biết: câu hỏi yêu cầu học sinh nhắc lại một kiến thức đã biết, học sinh chỉ dựa vào trí nhớ để trả lời.

- Mức 2 - Hiểu: Câu hỏi yêu cầu học sinh tổ chức, sắp xếp lại các kiến thức đã học và diễn đạt lại bằng ngôn ngữ của mình, chứng tỏ đã thông hiểu chứ không phải chỉ biết và nhớ.

- Mức 3 - Áp dụng: Câu hỏi yêu cầu học sinh áp dụng kiến thức đã học vào một tình huống mới, khác trong bài học. 
- Mức 4 - Phân tích: Câu hỏi yêu cầu học sinh phân tích nguyên nhân, hay kết quả của hiện tượng, tìm kiếm những bằng chứng cho một luận điểm.

- Mức 5 - Tổng hợp: Câu hỏi yêu cầu học sinh vận dụng phối hợp các kiến thức đã có để giải đáp một vấn đề khái quát hơn bằng sự suy nghĩ sáng tạo của bản thân.

- Mức 6 - Đánh giá: Câu hỏi yêu cầu học sinh nhận định, phán đoán về ý nghĩa của một kiến thức, giá trị của một tư tưởng, vai trò của một học thuyết, giá trị của cách giải quyết một vấn đề mới được đặt ra trong chương trình học tập.

\section{Sử dụng phương pháp dạy học vấn} đáp trong giảng dạy phần "Phương pháp cho trẻ khám phá khoa học về MTXQ”

Khi dạy chương 2, phần "Các hình thức tổ chức hướng dẫn trẻ khám phá khoa học về $M T X Q$ " giáo viên có thể sử dụng phương pháp vấn đáp với hai loại câu hỏi trên. Tùy vào đối tượng trẻ, có thể sử dụng câu hỏi dạng 1 hoặc dạng 2. Tuy nhiên, trong mỗi một bài dạy, bao giờ giáo viên cũng áp dụng cả 2 dạng câu hỏi trên từ tái hiện cho đến đánh giá.

- Hình thức dạo chơi trong thiên nhiên (dạo chơi có mục đích quan sát đối tượng) là nhu cầu không thể thiếu đối với trẻ mầm non. Nó mang lại cho trẻ không khí trong lành, thỏa mãn nhu cầu về vận động, nhu cầu tiếp nhận thông tin qua khám phá thiên nhiên. Mặt khác, giáo dục tình cảm cho trẻ biết yêu quý và bảo vệ thiên nhiên. Do đó, để giúp người học biết được mục đích của hình thức dạo chơi trong thiên nhiên thì giáo viên đưa ra câu hỏi yêu cầu người học dựa vào kiến thức đã biết, đã có của mình để trả lời. (áp dụng câu hỏi dạng 2).

"Việc tổ chưc hoạt động dạo chơ trong thiên nhiên cho trẻ có muc đích gì?"

- Góc hoạt động là khoảng không gian, nơi trẻ có thể được tự chọn và hoạt động tích cực theo nhu cầu và hứng thú của cá nhân, hoặc của nhóm nhỏ với những trẻ có cùng sở thích. Hoạt động góc giúp trẻ tìm hiểu, khám phá cái mới, hoạt động với đồ vật, rèn luyện kĩ năng. Để có các góc hoạt động thì người giáo viên mầm non phải biết thiết kế, xây dựng góc hoạt động phù hợp với độ tuổi, nội dung, và phải đảm bảo nguyên tắc xây dựng góc, nhưng điều quan trọng là phải biết cách thiết kế và tổ chức hoạt động góc như thế nào? Vì vậy khi dạy phần cách tổ chức hoạt động góc cho trẻ khám phá khoa học về môi trường xung quanh, giáo viên sử dụng 2 mức độ câu hỏi sau:

* Mức độ câu hỏi hiểu:

(1). "Trình bày khái niệm góc hoạt động?"

(2). "Bạn hiểu thế nào là choi và hoạt động ở các góc?”

* Mức độ câu hỏi áp dụng:

(1). Hãy thiết kế góc "thu viện" cho chủ đề "Nhũng con vật đáng yêu” ở lớp mẫu giáo lón?

(2). Thiết kế nội dung hoạt động "cho trẻ khám phá khoa học về môi truòng xung quanh" với chủ đề "Nước và các hiện tượng tụ nhiên" ở lớp mẫu giáo nhỡ?

Để giúp cho người học thấy rõ được hoạt động học là hoạt động chủ đạo để hệ thống hoá, khái quát hoá, mở rộng kiến thức cho trẻ. Do vậy, khi giảng dạy phần này giảng viên nên sử dụng câu hỏi ở cấp độ phân tích.

"Tại sao phải tổ chức hoạt động chung, hoụt động có chủ đích khi cho trẻ KPKH về MTXQ?"

- Hoạt động chung có chủ đích học tập được tổ chức thông qua các hoạt động giáo dục theo hệ thống chủ điểm, thể hiện sự phối hợp, hòa quyện và bổ sung cho nhau về các mặt giáo dục, nhằm phát huy tối đa khả năng của trẻ. Trong quá trình tổ chức hoạt động học, giáo viên mầm non phải biết kết hợp nội dung kiến thức 
của các môn khoa học phù hợp, cần biết tạo các tình huống có vấn đề để thúc đẩy khả năng cũng như sự hứng thú của trẻ. Để giúp người học có cái nhìn tổng quát, khi dạy phần "hoạt động chung có mục đích học tập" giáo viên cần sử dụng câu hỏi ở cấp độ tổng hợp, buộc người học phải sử dụng phối hợp các kiến thức đã có để giải đáp vấn đề một khái quát hơn bằng suy nghĩ sáng tạo của bản thân.

"Hãy thiết kế so" đồ tu duy về cách thưc hiện hoạt động chung có chủ đich học tập?"

Người học không chỉ nắm vững kiến thức đã học, điều quan trọng là phải thể hiện được quan điểm, thái độ, phán đoán của mình về vai trò, giá trị của các hình thức cho trẻ khám phá khoa học về môi trường xung quanh. Giáo viên sử dụng câu hỏi ở cấp độ đánh giá sau:

(1).Em có nhận xét gì về việc tổ chức hoạt động dạo chơi trong thiên nhiên cho trẻ ở các truò̀ng mầm non hiện nay?

(2). Có người cho rằng hoạt động chung có chủ đích hoc tập chỉ mở rộng kiến thức cho trẻ theo em đúng hay sai? Vì sao?

\section{Kết luận}

Tuy nhiên, do khuôn khổ của bài viết này, chỉ thể hiện được nội dung nhỏ trong học phần Phương pháp cho trẻ khám phá khoa học về môi trường xung quanh. Mặc dù vậy, việc vận dụng phương pháp vấn đáp vào giảng dạy học phần: "Phưong pháp cho trẻ khám phá khoa học về môi trương xung quanh" hệ cao đẳng mầm non là cần thiết, kích thích được tính tích cực hoạt động nhận thức của người học, qua đó hình thành kĩ năng sư phạm cần thiết cho sinh viên. Sử dụng phương pháp này còn giúp cho giáo viên nắm được trình độ nhận thức của học sinh một cách nhanh nhất, hiểu rõ được ưu điểm và hạn chế của sinh viên. Từ đó, kịp thời điều chỉnh hoạt động của mình và của người học, nhằm góp phần nâng cao chất lượng dạy và học học phần này.

\section{TÀI LIỆ THAM KHẢO}

1. Bộ Giáo dục và Đào tạo (2009), Chưong trình giáo dục mầm non các lứa tuổi;

2. Đặng Văn Đức - Nguyễn Thu Hằng (1998), Phuoong pháp dạy học theo hướng tích cực, Nxb Giáo dục;

2. Đặng Vũ Hoạt - Hà Thế Ngũ̃ (1997), Giáo dục học, tập 1, Nxb Giáo dục;

4. Hoàng Thị Oanh, Nguyễn Thị Xuân (2006), Phuơng pháp hướng dẫn trẻ làm quen môi truoòng xung quanh, Nxb Giáo dục;

5. Hoàng Thị Oanh (1993), Phương pháp hương dẫn trẻ làm quen MTXQ, Nxb Giáo dục. 